\title{
Teleworking in South Africa: Employee BENEFITS AND CHALLENGES
}

Authors:

Nicholas Baard

Adèle Thomas ${ }^{1}$

\section{Affiliations:}

${ }^{1}$ Department of Business

Management, University

of Johannesburg, Gauteng,

South Africa

\section{Correspondence to:}

Adèle Thomas

email:

adelet@uj.ac.za

\section{Postal address:}

Department of Business

Management, University of

Johannesburg, PO Box 524,

Auckland Park 2006,

South Africa

\section{Keywords:}

human resources practices management practices; survey; telecommuting; virtual working arrangements

\section{Dates:}

Received: 03 May 2010

Accepted: 24 Aug. 2010

Published: 28 Oct. 2010

How to cite this article: Baard, N., \& Thomas, A. (2010). Teleworking in South Africa: Employee benefits and challenges. $S A$ Journal of Human Resource Management/SA Tydskrif vir Menslikehulpbronbestuur, 8(1), Art. \#298, 10 pages. DOI: $10.4102 /$ sajhrm.

v8i1.298

This article is available at: http://www.sajhrm.co.za

(C) 2010. The Authors. Licensee: OpenJournals Publishing. This work is licensed under the Creative Commons Attribution License.

\begin{abstract}
Orientation: Virtual working arrangements present possible benefits to organisations and their employees. However, in South Africa, few organisations have implemented teleworking as a specific form of virtual work. The benefits and challenges to teleworkers are therefore largely unknown.
\end{abstract}

Research purpose: The present study aimed to identify employee perceptions of personal benefits and challenges of teleworking.

Motivation for the study: The study sought to contribute insights for South African business practice in this under-researched field.

Research design, approach and method: This exploratory study collected primary data through the distribution of an electronic questionnaire to 94 employees at three South African organisations, with a $67 \%$ response rate. The survey included both closed and open-ended questions that were analysed using a combination of quantitative and qualitative techniques.

Main findings: Most of the internationally identified benefits of teleworking were supported by participants, such as improved productivity, increased job satisfaction and organisational loyalty, decreased stress and improved work-life balance. Challenges identified included an increase in working hours and the lack of availability of training opportunities.

Practical/managerial implications: The possible employee benefits and challenges of teleworking may assist organisations in devising teleworking practices and procedures that leverage benefits and address challenges inherent in this form of work practice.

Contribution/value add: The study aims to supplement the dearth of knowledge about teleworking, specifically in the South African context, to assist organisations practically in their development of this form of virtual work arrangement for the benefit of organisations and their employees.

\section{INTRODUCTION}

\section{Key focus of the study}

Internationally, virtual working arrangements are increasingly becoming part of the traditional organisational structure (Ingham, 2006). However, the globally documented benefits of teleworking for employees and organisations, as a particular aspect of virtual working, have largely not been studied in South Africa. The present study aims to explore the perceived benefits to and challenges of teleworking for employees in three selected companies in South Africa.

\section{Background to the study}

In response to competitive imperatives, a visible artefact of the changing work environment is the global expansion of organisational boundaries (Watson-Manheim, Chudoba \& Crowston, 2002). In this regard, Helms and Raiszadeh (2002) and Thorne (2005) state that the creation of virtual organisations is the only response to the current chaos of global competition; Jackson, Gharavi and Klobas (2006) note how IT-enabled organisations are making greater use of virtual teams as an integral part of their operations. Kowalski and Swanson (2005) indicate that IBM ${ }^{\circledR}$, Boeing ${ }^{\circledR}, A T \& T ®$, Merrill Lynch $®$ and Hewlett-Packard $\AA$ are a few of the multinational organisations that are making a success of virtual working arrangements in their global operations, indicating the size and type of organisation that can adopt such a structure. According to Morgan (2004), Microsoft founder, Bill Gates claims that by $2050,50 \%$ of all workers globally will be virtual workers.

\section{Trends from the research literature}

In terms of international markets, the benefits of teleworking to employees have been noted to include increased job satisfaction and work life balance (Heneman \& Greenberger, 2002), increased productivity (Siha \& Monroe, 2006) and a reduction in stress related to the home environment, particularly for women (Martinez-Sanchez, Perez-Perez, Vela-Jimenez \& de-Luis Carnicer, 2008). Ahmadi, Helms and Ross (2000), however, note that disadvantages of teleworking can include isolation from colleagues and the organisation, lack of support from the organisation and reduced career opportunities. Studies have also noted an increase in stress related to teleworking employees' working environments wherein work and home life become inseparable (cf. Kowalski \& Swanson, 2005). Management experiences challenges in terms of developing policies and rewards that ensure that teleworking arrangements function optimally for the benefit of employees (including teleworkers) and the organisation as a whole (Macky, Gardner \& Forsyth, 2008). 


\section{Research objective}

The objective of the present study was to explore perceptions of the benefits and challenges posed by teleworking for employees in three selected South African companies.

\section{Potential value-add of the study}

A search conducted by the authors between 2000 and 2010 within the SABINET, Gale, Ebscohost and Emerald academic publication data bases for specific articles on teleworking in South Africa identified only four articles, (1) Odendaal and Roodt (2002) compare Australian and South African perspectives on implementing flexible work practices, (2) Horwitz, Bravington and Silvis (2006) identify key factors in the effectiveness and failure of virtual teams, (3) Nortje, van Brakel and Rensleigh (2004) discuss the context of the information environment within which teleworkers work and (4) Langa and Conradie (2003) explore the perceptions and attitudes of teleworking among public sector officials. The present study, accordingly, aims to contribute to this small existing body of theory on teleworking, specifically in the South African context, to assist organisations practically in their understanding and development of this form of virtual working arrangement for the benefit of organisations and their employees.

\section{Literature review}

\section{The virtual organisation}

The current global business environment is characterised by (1) an increasing scarcity of human and material resources as well as by (2) an increase in competition from existing and new global and local players (Akkirman \& Harris, 2005; Johnson, 2004; Siha \& Monroe, 2006). Demands such as these require that organisations are flexible to address competition effectively (Gibson, 2003). Conner (2003) highlights how, through virtual working arrangements, organisations can locate many business activities in low-wage countries, creating economies of scale for global operations and reducing input costs.

Panteli and Duncan (2004) and Shekhar (2006) note that there is not one universally accepted definition of virtual working arrangements. Helms and Raiszadeh (2002) describe four types of virtual working arrangements:

- A working environment which is $100 \%$ virtual, for example, internet organisations where all non-core business functions are outsourced.

- Hollow firms that, through workforce reduction and reengineered business processes, are 'doing more with less' (Helms \& Raiszadeh, 2002, p. 240).

- Those that outsource some of the non-core business functions.

- Virtual offices or teams that form part of the greater organisation but which operate virtually to a greater extent than the rest of the organisation.

Similarly, Conner (2003, p. 133) notes three degrees of 'virtualness':

- The teleworking or telecommuting arrangement where technology allows employees to work away from the office and each other.

- The front-line arrangement where front office activities are taken closer to the customer.

- The cyber link arrangement where many different organisations work together through technology to achieve set goals.

Shekhar (2006) describes the degree of 'virtuality' of organisations as the proportion of the activities of the organisation that are completed through non face-to-face interactions facilitated by information and communication technologies.

Akkirman and Harris (2005) describe the virtual workplace as one that is not bound by the traditional limitations of organisational structures, reporting relationships and job descriptions. Beasty (2005) notes that the difference between an office on site and an employee's spare bedroom is becoming increasingly insignificant with less of an effect on business activities. Tietze and Musson (2003, p. 439) suggest that changes to the duration of the working period, that is, to the timing of work and to the utilisation of work time, constitute 'the fundamental temporal structure that defines the experience of work'.

Within the virtual office, Helms and Raiszadeh (2002) indicate the possibility of four alternatives, each with their own distinctive benefits and challenges:

- Teleworking or telecommuting, the most common type of virtual employment, is an arrangement whereby an employee has a desk or office at the organisation but is able to work from home on an agreed basis a few days a week.

- 'Hotelling', common with consultancy firms, is where employees have no fixed offices or desks, but reserve spaces for the times when they will be present on the premises.

- Home workers are employees who work from home on a daily basis and never commute into the office.

- Fully mobile workers are those who do not have an office at all, but spend time on the road visiting customers and working from customers' premises on a full time basis, a common approach with sales people and auditors.

Johnson (2005) includes in his definition of the virtual organisation, managers based at their organisations' offices but who manage widely dispersed employees, as another alternative within the virtual office environment. Similarly, Siha and Monroe (2006, p. 456) include the group, 'occasional home worker', as part of the virtual working community, referring to those employees who extend working hours while at home utilising cellular telecommunications technology.

\section{Benefits of virtual working arrangements}

As with any business decision, ideally, prior to choosing a virtual working arrangement, the purpose and benefits sought for all stakeholders need to be clearly understood. The description of virtual organisations being revolutionary in nature and unconstrained by the material aspects of organisational structures, a view noted by Thorne (2005), needs to be tempered by considering the benefits and challenges posed by virtual working arrangements. Virtual working arrangements are not suitable for all employment types and need to be assessed by organisations in terms of appropriateness prior to embarking on any such arrangement (Baruch \& Yuen, 2000; Morgan, 2004; Watad \& Will, 2003).

Baruch (2003), Heneman and Greenberger (2002) and Ingham (2006) note that when considering virtual working arrangements, the main benefits sought by organisations relate to reducing the costs of physical accommodation, the streamlining of operations, increasing productivity and attracting and retaining employees through greater employee flexibility and loyalty. O'Brien and Hayden (2007) add two further reasons for the promotion and development of virtual working arrangements, (1) allowing organisations to manage variable workloads to deal with peak periods of demand and (2) creating additional and suitable coverage over the weekends or holidays for specific business areas. Kowalski and Swanson (2005), Morgan (2004) and Shekhar (2006) suggest that such practices also lead to greater customer service over extended hours, improved speed with which organisations can respond to and resolve customer issues as well as enable the sourcing of specialised staff who may be spread across the globe.

Virtual working arrangements are sometimes used as reward mechanisms, allowing dedicated and hardworking employees to work from home, thereby building trust and loyalty between employees and management (Kurland \& Egan, 1999). In this regard, Heneman and Greenberger (2002) and Johnson (2004) 
note how virtual workers often remain at the organisation for longer periods, positively affecting employee retention and reducing hiring costs. In this vein, Wilsker (2008) found that $64 \%$ of employees would turn down a $20 \%$ pay rise if they could continue working according to a virtual arrangement. Nonwage benefits can also be as effective in retaining employees as paying higher than market related salaries (Kowalski \& Swanson, 2005) and can improve employees' morale, job satisfaction and work-life balance (Hamilton, Gordon \& Whelan-Berry, 2006; Martinez-Sanchez et al., 2008). Wilsker (2008) states that the average full-time teleworker within a virtual working arrangement in the USA, regardless of salary scale, receives an annual salary increase of $\$ 8400$ due to the reduced expenses that result from teleworking (vehicle, clothing, parking, food and insurance costs). Wilsker (2008) further notes that organisations can annually add \$20 000 per full-time teleworking employee to their bottom lines if all potential savings to the organisation are calculated. Meadows (2007) indicates a reduction in sick leave as another financial benefit to organisations utilising teleworking arrangements.

Martinez-Sanchez et al. (2008) add that women may derive the most benefit from virtual working arrangements, specifically teleworking arrangements, because of family commitments and Ahmadi et al. (2000) note that virtual working arrangements can assist employees in reducing home stress and can afford dual-career couples a balance between work and home life. Johnson (2004) states that such family-friendly employment policies are increasingly being used as tools to attract and retain employees and to encourage women to return to the workforce. Kepczyk (1999) and Patrickson (2002) observe that organisations are able, through virtual working arrangements, to include people who were previously excluded from the employee pool due to parental responsibilities, being physically disabled or being unable to travel the distance required from home to office. This is an important benefit in times of global scarcity of talented human capital (Heneman \& Greenberger, 2002). Virtual working arrangements may also encourage older workers in semi-retirement to remain employed for a few days a week, ensuring potentially sound work output. Older workers usually experience fewer interruptions due to the absence of children within the home environment (Patrickson, 2002).

While the above mentioned benefits apply to virtual working arrangements, the specific benefits of teleworking include an increase in productivity (Siha \& Monroe, 2006) and a willingness on the part of employees to work harder (Kowalski \& Swanson, 2005; Mann, Varey \& Button, 2000). In this regard, Kepczyk (1999) states that quieter, more focused work environments with fewer interruptions, the freedom to work in comfort and the absence of office politics are often translated into increased employee productivity. Ilozor and Ilozor (2002) report that job satisfaction is higher in teleworkers than in other employees because of a reduction in stress levels.

Increasing traffic congestion may be a motivating factor for embarking on virtual working arrangements (Siha \& Monroe, 2006). This factor is pertinent within the South African context with its annual increase of $5.2 \%$ in vehicles and with the cost of accidents during the 2007-2008 period totalling R13.27 billion (Road Traffic Management Corporation, 2008). Sperling and Yeh (2009) note how the increase in vehicles adds to the already overburdened road infrastructure and to growing pollution in the country. Beastley, Lomo-David and Seubert (2001) note that teleworking results in less impact on the environment and thus contributes positively to society at large. Siha and Monroe (2006) suggest that virtual working arrangements may be used in future as a carbon offsetting or reduction technique, thereby allowing organisations to avoid paying the penalties of additional taxes that may be imposed for exceeding set carbon emission quotas. In addition, Siha and Monroe (2006) note that the average worker spends 400 hours a year travelling to and from work and being caught up in inner city traffic congestion, all of which contribute to lost and unproductive hours.

\section{Challenges of virtual working arrangements}

In seeming contrast to the growing awareness of virtual working arrangements internationally, $\mathrm{O}^{\prime}$ Brien and Hayden (2007) state that the actual adoption of virtual working arrangements is still a passive strategy within the business world and is not taken seriously enough to be implemented as part of corporate-wide strategy. Kowalski and Swanson (2005) advance that the reasons for this lack of implementation include the perception that teamwork suffers, the potential negative impact on employees who have less time to socialise with co-workers, organisational information security concerns and the lack of global reach of broadband technologies. To these perceived constraints, Johnson (2004) and Martinez-Sanchez et al. (2008) add that (1) flexible working arrangements are not always viewed as priority in business, (2) the perception exists that those who work flexible hours are not really working and (3) a belief exists that it is difficult to manage staff who work flexible hours.

Some of the challenges to organisations considering the establishment of virtual working arrangements (Kepczyk, 1999) include:

- Insurance of the home office environment and the equipment contained therein.

- Security requirements relating to equipment and data movement.

- Local laws governing activities at private residences.

- The provision of remote technical support.

Legal issues surrounding virtual working arrangements and insurance, compensation and other such issues differ between countries and have not yet been established (Tidd, 1999). O'Brien and Hayden (2007) note that the abuse of information technology and communication tools, such as using equipment for personal use or allowing family members access to such resources, is a potential downside of virtual working if employees are not properly managed throughout the process. Johnson (2004) suggests that virtual working arrangements negatively impact the level of commitment of teleworkers to their organisations, requiring employee incentives that encourage such commitment to be devised and revised continuously.

For the individual virtual worker, Ahmadi et al. (2000) and Mann et al. (2000) document the following disadvantages of teleworking:

- isolation

- longer working hours

- lack of support

- less sick leave

- reduced career progression.

These issues demand considerable management attention. Lim and Teo (2000) and Horwitz et al. (2006) note that full time virtual workers may enjoy fewer promotions in the work environment due to the lack of opportunities for employees to engage in networking activities. Conner (2003) highlights that virtual workers do not have immediate colleagues against whom they can compare their productivity which hampers benchmarking or comparison of performance and progress. He suggests that this absence can result in weaker performance caused by a lack of exposure to positive peer pressure and can lead to increased feelings of isolation. Moustafa-Leonard (2007, p. 197) notes how manager-subordinate trust can be negatively impacted by virtual work arrangements due to the little face-toface interaction 'creating risk and uncertainty as cornerstones of this dyadic relationship'.

Horwitz et al. (2006) stress that virtual workers often have difficulty in separating work from private life, particularly when work involves liaising with colleagues in different time zones. Tietze and Musson (2003) state that not only the teleworker, but also other residents in the home are often 
unprepared for integrating paid work into the household. In this regard, Kowalski and Swanson (2005) and O'Brien and Hayden (2007) refute one of the most commonly cited benefits of teleworking, that is to say, work-life balance, noting that having to address family responsibilities during work hours actually increases stress among teleworkers.

Kepczyk (1999) and Allert (2001) believe that it is essential to the success of virtual working arrangements that the right people are recruited as teleworkers at the outset. Employees need to be able to work in a virtual work arrangement, away from direct management and colleagues and should possess a sound balance of technical and interpersonal skills (Horwitz et al., 2006). Tietze and Musson (2003) include self-discipline as one of the key personal characteristics of a good virtual worker. When considering the characteristics of effective virtual teams, employees who may experience problems could be expected to be:

- Those who may have difficulty in operating as empowered professionals using their initiative (Hunsaker \& Hunsaker, 2008).

- Those who miss informal work and non-work related conversations (Furst, Reeves, Rosen \& Blackburn, 2004).

- Those who experience difficulties with interdependence (Dafoulas \& Macauley, 2002).

- Those who find it demanding to fulfil their work functions through computer-mediated technology (Hunsaker \& Hunsaker, 2008)

\section{Technology}

New wireless communication and data technologies are constantly improving, bringing faster data transfer speeds to the mobile worker, resulting in minimal difference between network and mobile connectivity (Nandhakumar \& Baskerville, 2006). Bal and Teo (2001) and Watad and Will (2003) mention the advantageous use of audio and video conferencing tools for meetings within virtual teams. Real time sharing of data and presentations are now possible with all participants present (Curseu, Schalk \& Wessel, 2008). Other tools readily available include online chat forums or software such as Google Talk $\circledR_{,}$ Skype ${ }^{\circledR}$ and Windows Instant Messaging ${ }^{\circledR}$. Stanford (2003) notes the use of such technology in facilitating quick and easy communication at reduced costs between virtual employees themselves and between virtual employees and their managers. Integrated and intensive e-HR platforms also enable virtual employees to resolve queries themselves without having to contact human resources (HR) departments. Investment in technology, accordingly, is a prerequisite for the successful operation of virtual organisations (Shekhar, 2006; Siha \& Monroe, 2006), often resulting in a definite increase in certain hardware costs that reduce potential savings made on office space when first embarking on virtual working arrangements (Kowalski \& Swanson, 2005; Mann et al., 2000).

Nevertheless, it is the actual people who ensure the effectiveness of virtual working arrangements, technology is only the enabler (Akkirman \& Harris, 2005; Vakola \& Wilson, 2004). In this respect, it is essential that effective communication exists along with trust between employers and employees (Siha \& Monroe, 2006). Panteli and Duncan (2004, p. 423) underscore this sentiment, noting that 'virtuality requires trust to make it work; technology on its own is not enough' particularly with little face-to-face time and with social relationships under pressure (Helms \& Raiszadeh, 2002). A large component of interpersonal communication is not what is said, but the tone that is used, the accompanying body language and facial expressions, the pitch of the speaker's voice and how the message is delivered (Sundaram \& Webster, 2000). The absence of these elements when communicating virtually can have an important impact on the conveyed message. Mann et al. (2000) state that computer mediated communication removes the ability to communicate emotion, an essential part of the communication and understanding process and can bring with it a new set of complications and challenges for virtual workers and management. For geographically dispersed virtual workers, information processing and communication problems may be exacerbated by time zones, different country norms and different languages spoken (Hughes \& Love, 2004).

\section{Implementing virtual working arrangements}

Lardi-Nadarajan (2008) notes the necessity for a gradual transition to virtual working, as well as both management and employee support for the initiative. Moving towards virtual arrangements requires the transformation of large parts of the existing organisational structure which takes time to develop and document (Lardi-Nadarajan, 2008; Siha \& Monroe, 2006) and requires new human resource approaches (Heneman \& Greenberger, 2002).

According to Thorne (2005), there are no clear guidelines for developing virtual working teams to indicate how best to deal with strategy, information systems and accounting practices. Accordingly, Bal and Teo (2001), Kowalski and Swanson (2005) and Morgan (2004) recommend benchmarking, including the benchmarking of processes, as a tool to determine how organisations that have embarked on virtual working arrangements are performing against other organisations. Kowalski and Swanson (2005) further note that the areas that need to be considered in the success of virtual working arrangements include:

- Support from all areas of management, especially direct supervisor encouragement.

- Technological support and the provision of necessary tools along with appropriate training.

- Sound communication and trust across all levels and all relationships.

Horwitz et al. (2006) state that managers who exhibit a need to control people are unlikely to succeed as managers of employees in virtual settings. Relinquishing control over employees and affording them more freedom, however, should not detract from the manager's role as mentor and evaluator of daily performance (Morgan, 2004). Managers of virtual employees have to provide employees with greater support and positive feedback more than do managers operating in traditional settings (Horwitz et al., 2006). The management of virtual workers, however, requires a shift in management approach from measuring 'process' to measuring 'output' (Stanford, 2003) and, accordingly, calls for clear work requirements and a careful balance between virtual and face-to-face meetings which need to be maintained in order to retain the interpersonal balance between virtual employees and management. The global multi-generational workforce (Dwyer, 2009) presents additional challenges to management in terms of the policies, reward structures and the technology introduced to ensure success in virtual working arrangements (Macky, Gardner \& Forsyth, 2008)

Various authors (cf. Allert, 2001; Curseu et al., 2008; Kurland \& Egan, 1999; Stanford, 2003) refer to the importance of creating opportunities for regular and formal face-to-face discussions between management and employees who work virtually with regard to work issues and performance. Siha and Monroe (2006) go further by cautioning the use of emails in trying to address employee problems or in conveying criticism, suggesting that critical areas of the work relationship must still be addressed in person in order to promote and retain relationships and open communication.

Curseu et al. (2008) state that without the presence of an effective leader within a team of virtual workers, focus will be lost and the difficulties of working virtually may outweigh the benefits. Management needs to ensure that virtual workers are an integral part of the greater organisation and this demands that the larger organisational culture is transmitted to virtual workers, including the transmission of established norms 
and values that form common ground between the body of employees and the virtual worker. In this regard, Moore (1999) notes that the diverse cultures that are present within the South African workplace create additional complexity in managing and maintaining the organisational culture linking virtual workers to the macro work environment.

The sense of belonging and pride that workers experience as part of a large organisation is difficult to retain in the long term with virtual workers and, accordingly, managers need to focus on developing and maintaining these elements to promote employee retention (Jackson et al., 2006). The strength of organisational identification and association is critical to the successful management of virtual workers and is important in understanding the employee's need for affiliation and social support (Wiesenfeld, Raghuram \& Garud, 2001). Similarly, Porter and Kakabadse (2006) stress the need for managers to be aware of employees who are susceptible to overworking themselves, who will ultimately burn themselves out and who will, for that reason, no longer function optimally. In this regard, they note the importance of the development of an organisational culture that recognises a work-life balance.

Implementing virtual working arrangements involves many changes in the organisation, for example, how it operates, how it communicates and how employees function. These changes need to be understood and planned prior to the introduction of this organisational initiative to ensure that the resistance to change does not prevent the successful implementation of the virtual working arrangement (Diefenbach, 2007; Smith, 2005). Establishing the willingness and readiness of the organisation and its employees to accept change should be undertaken early as it impacts how and what change can and will be implemented (Meyer, Srinivas, Lal \& Topolnytsky, 2007). With regard to virtual working arrangements, change will need to be managed in terms of both the employees who are moving into such arrangements and those who remain in the traditional office environment.

\section{RESEARCH DESIGN}

\section{Research approach}

The present study is exploratory in nature, as the field under investigation has commanded little research attention in South Africa. To collect primary data, a cross sectional field survey was utilised, involving teleworkers from three large South African organisations in order to determine their perceptions about the benefits and challenges of this form of virtual working arrangement. Teleworking was regarded as an activity that involved participants working from home at least 1 day every week, but less than 5 days a week, while still maintaining a regular desk space at an office of the organisation (Helms \& Raiszadeh, 2002). The survey included both closed and openended questions that were analysed using a combination of quantitative and qualitative techniques. The open-ended questions sought to elicit additional insights to supplement the quantitative survey data.

\section{Research method}

\section{Research participants}

A purposive sample of three South African organisations that had embarked upon active teleworking arrangements in particular departments was used. One organisation is a large cellular telecommunications company and the other two are large companies in the financial sector. At the commencement of the study, with a view to including as many companies as possible, several companies that appeared to engage in forms of virtual working practices were approached. However, most of these companies could not be included in the present study as they had no formal policy or common understanding of teleworking or did not practice teleworking according to the definition adopted for this study. The dearth of companies incorporating teleworking practices according to the definition employed in this study, rendered only a small base from which to draw the sample. To preserve anonymity, the names of the companies that participated in the study were omitted. The entire population from each teleworking department in each company was included in the study $(n=94)$ with those 63 participants who returned questionnaires comprising the sample, giving a response rate of $67.0 \%$. While not all 63 participants answered all questions, response rates did not fall below 61 participants for any question.

The sample comprised 34 males (54.0\%) and 29 females (46.0\%) with 21 participants $(33.3 \%$ ) between the ages of 23 and 34 years, 24 participants $(38.1 \%)$ aged $35-40$ years and 18 participants $(28.6 \%)$ being over the age of 40 years. Nine participants (14.3\%) were Black (i.e. African, Coloured and Indian) and 53 participants $(84.1 \%)$ were White. One participant did not identify his or her race. Eighteen participants (28.6\%) occupied senior management positions, $22(34.9 \%)$, lower or middle management positions and 23 participants $(36.5 \%)$ did not fall into any management category. Forty-five participants (71.4\%) reported having one or more dependants living at home. The majority of participants (42 participants or $66.7 \%$ ) indicated that they had been teleworking for less than 2 years at their current organisations.

\section{Measuring instrument}

A questionnaire was constructed containing closed and open-ended items, drawing on the major benefits and challenges of teleworking noted in the literature. The first section of the questionnaire required participants to indicate demographic details as well as the nature of the teleworking arrangement in which they were involved. The second section of the questionnaire commenced with questions regarding employees' personal desire to increase teleworking ('Would you like to work from home more than you currently do?') where simple-dichotomy, frequency-determination and dichotomous-alternative questions (Zikmund, 2003) were used in order for participants to differentiate between particular alternatives. This section also included more specific questions relating to perceived benefits and challenges of teleworking, where a five-point Likert-type scale was used to determine the degree of respondent attitudes (Grover \& Vriens, 2006). An example of questions included 'Teleworking results in greater loyalty to my organisation'. Within this section, an item on the questionnaire required participants to provide their views regarding the possible compensation that teleworking could offer in place of salary increases. This question demanded only a 'yes' or 'no' response. The third section of the questionnaire concluded with open-ended questions that aimed to acquire additional information on the topic under review that may not have been gained through the closed-ended questions (Grover \& Vriens, 2006).

\section{Research procedure}

A pilot test of the questionnaire was undertaken with a group of participants who engage in teleworking but who were not part of the research population at any of the companies in the study, as recommended by Reynolds, Diamantopoulos and Schegelmilch (1993). The pilot test led to a change in sequencing of questions to ensure that later responses were not influenced by prior questions.

Senior management approved the questionnaire prior to the questionnaires being distributed electronically to participants during June and July 2009 via the intranets of the three companies. Participants were informed that participation in the study was voluntary and were afforded the opportunity of refusing to participate or stopping midway during the answering of the questionnaire if they deemed it necessary. They were assured of complete confidentiality.

After the data collection period, ten participants were contacted to verify selected answers given to a particular number of 
questions in order to assess the reliability of the responses by confirming that the same participant gave the same answers to selected questions for the second time.

\section{Data analysis}

Descriptive statistics were used to summarise the data. While participants could record their responses to questions on a fivepoint scale in the second section of the questionnaire, the five categories were collapsed into three categories (i.e. positive, neutral and negative) for ease of analysis. Seeing as a nonprobability sampling method was used and the sample size was relatively small, non-parametric tests were used to test associations between variables. Tests used included the Pearson Chi-square and Kruskal-Wallis tests. The relationships tested included, (1) gender and interest expressed by participants about increasing teleworking activity, (2) teleworking and having dependants at home, (3) teleworking and family time, (4) teleworking and work-life balance, (5) teleworking and stress levels and (6) teleworking and working longer hours. Content analysis, through systematic and objective observation of responses, was used to analyse data from the open-ended questions in order to identify common themes, as recommended by Babbie and Mouton (2009).

\section{RESULTS}

\section{Perceived benefits of teleworking}

Over half of the participants (57.1\%) indicated that they would prefer to work from home more than they currently do. Table 1 indicates the most commonly reported benefits of teleworking by participants (in some instances only 62 of the 63 participants answered the question).

Table 1 seems to be suggesting that the majority of participants perceived that teleworking affords them most of the internationally accepted benefits associated with the practice, such as:

- less distraction and greater productivity

- greater work flexibility and increased job satisfaction

- increased morale and organisational loyalty

- greater work-life balance

- less stress

- somewhat of a reduction in monthly expenses.

However, training opportunities for participants appeared to have increased only in a limited way, with $44.4 \%$ reporting that training opportunities had not increased at all or had

TABLE 1

Benefits of teleworking

\begin{tabular}{|c|c|c|c|c|c|c|}
\hline \multirow[t]{3}{*}{ Benefits experienced } & \multicolumn{6}{|c|}{ Number and percentage of participants } \\
\hline & \multicolumn{2}{|c|}{ Limited or no extent } & \multicolumn{2}{|c|}{ Neutral } & \multicolumn{2}{|c|}{ Great extent } \\
\hline & $n$ & $\%$ & $n$ & $\%$ & $n$ & $\%$ \\
\hline Less distraction & 4 & 6.4 & 5 & 7.9 & 54 & 85.7 \\
\hline Improved productivity & 1 & 1.6 & 8 & 12.9 & 53 & 85.5 \\
\hline Greater flexibility in work arrangement & 4 & 6.4 & 6 & 9.5 & 53 & 84.1 \\
\hline Increased job satisfaction & 6 & 9.5 & 5 & 7.9 & 52 & 82.5 \\
\hline An improved work-life balance & 9 & 14.5 & 6 & 9.7 & 47 & 75.8 \\
\hline A greater loyalty to the organisation & 7 & 11.3 & 10 & 16.1 & 45 & 72.6 \\
\hline Increased morale & 4 & 6.4 & 14 & 22.2 & 45 & 71.4 \\
\hline Decreased stress levels & 9 & 14.5 & 14 & 22.6 & 39 & 62.9 \\
\hline Reduced monthly expenses & 15 & 23.8 & 16 & 25.4 & 32 & 50.8 \\
\hline Increased time spent with family & 11 & 17.5 & 23 & 36.5 & 29 & 46.0 \\
\hline Decreased sick days & 13 & 20.6 & 21 & 33.3 & 29 & 46.0 \\
\hline Increased number of training opportunities & 28 & 44.4 & 27 & 42.9 & 8 & 12.7 \\
\hline
\end{tabular}

$n=$ Number of participants.

$\%=$ Percentage of participants.

TABLE 2

Challenges of teleworking

\begin{tabular}{|c|c|c|c|c|c|c|}
\hline \multirow[t]{3}{*}{ Challenges } & \multicolumn{6}{|c|}{ Number and percentage of participants } \\
\hline & \multicolumn{2}{|c|}{ Disagree } & \multicolumn{2}{|c|}{ Neutral } & \multicolumn{2}{|c|}{ Agree } \\
\hline & $n$ & $\%$ & $n$ & $\%$ & $n$ & $\%$ \\
\hline Working longer hours & 9 & 14.8 & 12 & 19.7 & 40 & 65.6 \\
\hline $\begin{array}{l}\text { Differing teleworking team culture as opposed to culture of the } \\
\text { larger organisation }\end{array}$ & 14 & 22.6 & 22 & 35.5 & 26 & 41.9 \\
\hline $\begin{array}{l}\text { Lack of organisational assistance in the physical setup of the } \\
\text { home-office environment }\end{array}$ & 15 & 24.2 & 30 & 48.4 & 17 & 27.4 \\
\hline $\begin{array}{l}\text { Lack of organisational support for the purchase of home office } \\
\text { equipment }\end{array}$ & 26 & 41.9 & 21 & 33.9 & 15 & 24.2 \\
\hline Change in the trust relationship between superior and teleworker & 31 & 50.0 & 17 & 27.4 & 14 & 22.6 \\
\hline $\begin{array}{l}\text { Required to resolve own technical issues that would normally be } \\
\text { resolved by a technical specialist at the office }\end{array}$ & 31 & 50.0 & 17 & 27.4 & 14 & 22.6 \\
\hline Problematic network connectivity to the organisation & 41 & 66.1 & 8 & 12.9 & 13 & 21.0 \\
\hline $\begin{array}{l}\text { Increase in number of interpersonal communication difficulties } \\
\text { with colleagues }\end{array}$ & 41 & 66.1 & 13 & 21.0 & 8 & 12.9 \\
\hline Lack of organisational investment in new technology & 32 & 51.6 & 22 & 35.5 & 8 & 12.9 \\
\hline Greater stress experienced by families & 49 & 79.0 & 6 & 9.7 & 7 & 11.3 \\
\hline More attention required to address family relationships & 43 & 69.4 & 12 & 19.4 & 7 & 11.3 \\
\hline Irregular feedback from supervisor & 40 & 64.5 & 17 & 27.4 & 5 & 8.1 \\
\hline Being overlooked for promotion & 45 & 72.6 & 13 & 21.0 & 4 & 6.5 \\
\hline Feelings of isolation from the organisation and co-workers & 44 & 71.0 & 14 & 22.6 & 4 & 6.5 \\
\hline $\begin{array}{l}\text { Lack of organisational commitment to the teleworking } \\
\text { arrangement }\end{array}$ & 50 & 82.0 & 7 & 11.5 & 4 & 6.5 \\
\hline Output not measured & 52 & 84.0 & 7 & 11.3 & 3 & 4.8 \\
\hline Problematic communication with superiors & 53 & 85.5 & 6 & 9.7 & 3 & 4.8 \\
\hline Lack of clear expectations established by superiors & 55 & 90.2 & 4 & 6.6 & 2 & 3.3 \\
\hline Poor organisational facilitation of the change to teleworking & 50 & 80.7 & 10 & 16.1 & 2 & 3.2 \\
\hline
\end{tabular}

Poor organisational facilitation of the change to teleworking

$=$ Number of participants

$\%=$ Percentage of participants. 
increased only to a limited extent; many of the participants $(42.9 \%)$ responded neutrally to this item. Mixed findings were reported in terms of the perceived benefits of being employed as teleworkers, such as an increase in time spent with family and a decrease in the amount of sick days taken. While participants noted these factors to be less important in terms of benefits than those listed above, nevertheless, to some extent, these factors were still regarded as benefits by some participants.

With regard to a separate question that asked participants whether they regarded the option of teleworking as an acceptable replacement for a salary increment, despite the benefits reported in Table 1, the majority of participants ( 45 or $71.4 \%$ ) did not regard the option of teleworking as an acceptable replacement for a salary increase.

\section{Perceived challenges of teleworking}

Table 2 details the perceived challenges of teleworking as noted by participants against those challenges described in the international literature (in some instances, only 61 or 62 of the 63 participants answered the question).

As indicated in Table 2, many of the internationally reported challenges, personal to the teleworker, were not perceived by participants as challenges, with the exception of working longer hours. Participants appeared to be divided on the issues relating to support offered by their organisations in terms of purchasing home office equipment and providing assistance in setting up the home-office environment. A number of participants also reported a difference in the organisational team culture between those who telework and the larger organisation to which they belong.

\section{Additional identified benefits and challenges of teleworking}

Participants were asked in open-ended question format to identify any particular benefits and challenges of teleworking that were not addressed in the questionnaire. Thirty-six participants provided additional comment in terms of the benefits and 25 participants provided comment in terms of the challenges.

TABLE 3

Additional benefits of teleworking

\begin{tabular}{lcc}
\hline Additional benefits & \multicolumn{2}{c}{ Number of participants $(\boldsymbol{n}=\mathbf{3 6})$} \\
\cline { 2 - 3 } & $\boldsymbol{n}$ & $\%$ \\
\hline Not wasting time in traffic & 16 & 44.4 \\
Ability to deal with sick children and parents & 11 & 30.6 \\
Increased quality of time spent with family & 5 & 30.6 \\
Ability to work longer hours and over the weekend & 5 & 13.9 \\
Ability to increase face time with customers & 5 & 13.9 \\
Increased self-discipline* & 4 & 13.9 \\
Ability to improve eating habits for whole family & & 11.1 \\
and attend gym* & 3 & 8.3 \\
$\begin{array}{l}\text { Change in focus from person to the output of work } \\
\text { Increased free time over weekend due to }\end{array}$ & 1 & 2.8 \\
arranging for repair work and domestic staff to \\
work and be monitored during the week \\
$\begin{array}{l}\text { Ability to work and smoke at the same time, no } \\
\text { time wasting* }\end{array}$ \\
$\begin{array}{l}n=\text { Number of participants. } \\
\%=\text { Percentage of participants. } \\
\text { *indicates new issue not commonly noted in the literature. }\end{array}$
\end{tabular}

TABLE 4

Dependants at home and benefits or challenges of teleworking

\begin{tabular}{lll}
\hline $\begin{array}{l}\text { Number of dependants at home } \\
\text { measured against }\end{array}$ & Kruskal-Wallis $\chi^{2}$ & $p$ \\
\hline Improved work life balance & 12.69 & 0.005 \\
Increased time spent with family & 11.57 & 0.009 \\
Decreased stress levels & 10.26 & 0.016 \\
Longer work hours & 8.92 & 0.030 \\
\hline
\end{tabular}

From Table 3 it can be seen that the most frequently cited additional benefits of teleworking in response to the openended questions was that less time was wasted in traffic by not travelling to the office during peak hours, followed by increased flexibility and family time - all commonly agreed benefits of teleworking - and ones that echoed the findings noted in Table 1. Unique comments included being more selfdisciplined, improved eating habits and the ability to work and smoke at the same time. These findings primarily relate to the personal benefits of teleworking for employees, as opposed to the work-related benefits of this practice.

All additional comments relating to the challenges of teleworking could be grouped with the attributes (previously identified in Table 2) and were ones of a personal nature, including the impact that this arrangement has had on the teleworker. However, the tendency to work longer hours was specifically stressed in line with the finding that the majority of participants $(65.6 \%)$ identified longer working hours as the main challenge of teleworking (Table 2).

\section{Selected associations between teleworking and other variables}

The relationship between gender and desire to increase teleworking activity was explored because there were roughly the same number of men (34) and women (29) in the sample and because issues of work and family balance are often suggested as being more important to women than to men (MartinezSanchez et al., 2008). A statistically significant relationship was observed between gender and desire to increase teleworking activity $\left(\chi^{2}=10.48, d f=1, p=0.001\right)$, with proportionally more men than women indicating a desire to work from home more than they currently do.

Table 4 indicates the association between dependants at home (e.g. 0 dependants, 1-2 dependants, $3+$ dependants) and the benefits and challenges of teleworking.

As indicated in Table 4, a significant association was found between the number of dependants at home and an improvement in work-life balance since teleworking $\left(\chi^{2}=12.69, p=0.005\right)$, with a higher proportion of participants who have three or more dependants at home more likely to express improvement in work-life balance. A significant association was found between the number of dependants at home and the increased time participants spent with family since teleworking $\left(\chi^{2}=11.57\right.$, $p=0.009$ ), with a higher proportion of participants who have three or more dependants indicating the greatest increase in time spent with family. Again, a significant association was found between the number of dependants at home and a decrease in stress levels since teleworking $\left(\chi^{2}=10.26, p=0.016\right)$, with a higher proportion of participants having three or more dependants at home reporting a decrease in stress levels than those who have no dependants or have one or two dependants. A significant association was also found between the number of dependants at home and working longer hours since teleworking $\left(\chi^{2}=8.921, p=0.030\right)$, with a higher proportion of participants with no dependant or only one dependant at home, indicating an increase in working hours since teleworking.

\section{DISCUSSION}

Although, internationally, virtual workers are increasingly becoming part of the traditional organisation, the anticipated employee benefits and challenges of teleworking, a specific form of virtual work, have largely not been investigated in the South African context. The study sought to understand the perceptions of teleworkers at three South African companies with regard to the challenges and benefits of this form of work arrangement. As a result, the overall objective of the study was addressed by highlighting the perceptions reported by participants of such benefits and challenges. It is hoped 
that the present study will contribute to the consideration of teleworking as a form of work arrangement at South African organisations.

The findings support the internationally identified benefits of teleworking, such as:

- increased productivity (Siha \& Monroe, 2006)

- greater organisational loyalty (Siha \& Monroe, 2006)

- increased morale and job satisfaction (Hamilton et al., 2006)

- additional flexibility (Mann et al., 2000)

- increased family time and work-life balance (MartinezSanchez et al., 2008)

- decreased stress (Ahmadi et al., 2000)

- fewer monthly expenses (Wilsker, 2008)

- less sick days taken (Meadows, 2007).

In addition, participants appeared not to identify many of the challenges associated with this virtual working arrangement as documented in the literature, viz. a lack of technological and organisational support for teleworking, including the poor facilitation of change to this working arrangement (Kowalski \& Swanson, 2005; Shekhar, 2006). Unlike findings reported by Akkirman and Harris (2005), Johnson (2004), Panteli and Duncan (2004), Siha and Monroe (2006), Thorne (2005) and Vakola and Wilson (2004), trust relationships and communication with superiors were not indicated as areas of concern for participants. Similarly, in contrast to various studies, participants did not report:

- decreased levels of trust and commitment to the organisation (Sundaran \& Webster 2000)

- irregular feedback, interpersonal communication difficulties and being overlooked for promotion (Horwitz et al., 2006)

- the absence of clear work expectations (Mann et al., 2000)

- the absence of measurement of output (Horwitz et al., 2006)

- feelings of isolation (Ahmani et al., 2000)

- problems with family relationships (Kowalski \& Swanson, 2005)

- greater family stress (Horwitz et al., 2006).

However, participants did report that working longer hours was a challenge in line with the findings of Ahmani et al. (2000) and Mann et al. (2000) and a significant association was found between the number of dependants at home and working longer hours. A higher proportion of participants with no dependants or with only one dependant at home, indicated the highest increase in working hours since teleworking.

Over half of the participants (57.1\%) indicated that they would prefer to work from home more than they currently do, possibly indicative of the positive experience of teleworking and that the current arrangement must, to a large degree, work for them, their families and their organisations. Significantly, men, more so than women, expressed a desire to work from home more than they currently do, indicating that teleworking may not primarily benefit women as it was originally intended (Martinez-Sanchez et al., 2008) possibly due to the emergence of dual-career families and the related change in family dynamics.

Mixed views with regard to the time spent with family since teleworking were reported in line with the findings of Kowalski and Swanson (2005). However, this finding could have been influenced by participants who are single or divorced $(12.7 \%)$, those who do not have any dependants living at home $(28.6 \%)$ or those who are in the youngest age group $(33.3 \%)$ who may possibly choose to spend additional free time with friends and not family. However, for those participants who had dependants living at home, teleworking appears to have promoted increased family time. In contrast to $\mathrm{O}^{\prime}$ Brien and Hayden (2007) who found that $70 \%$ of teleworkers experience stress from having to deal with family responsibilities when working at home, an increase in the number of dependants at home was positively associated with flexibility, time spent with family by the teleworker and decreased levels of stress.
The finding that over $50 \%$ of participants reported a general reduction in their monthly expenses since teleworking (cf. Helms \& Raiszadeh, 2002; Mann et al., 2000; Wilsker 2008) could suggest that teleworking, if compatible with job requirements, may be a human resources tool for retaining and rewarding staff over the long term in order to build and maintain a competitive workforce. However, the majority of participants did not believe that teleworking could substitute for remuneration, contrary to the findings of Martinez-Sanchez et al. (2008) and Wilsker (2008), a possible explanation for which could be the current economic downturn in the country.

Output-based performance management, the preferred performance measurement technique for teleworking (Stanford, 2003; Tietze \& Musson, 2003), could possibly have contributed to the reported increased productivity. Participants stated that they were given clear guidelines of what is expected of them as well as regular feedback, ensuring that any uncertainty is quickly resolved and that little ambiguity and confusion is present when working virtually. Removing the physical organisational boundaries by allowing employees to telework should not result in removing the institutional factors that afford employees direction and purpose within the organisation

One benefit mentioned by participants that does not appear prominently in the international literature is the ability of teleworkers to improve their lifestyles by leading a healthier lifestyle through eating better meals and attending the gym more often

Participants indicated that their companies effectively facilitated the change to teleworking and were committed to the teleworking arrangement. These actions may have contributed towards the positive trust and communication noted which, in turn, may positively impact morale and reported increased job satisfaction (Johnson, 2004; Kowalski \& Swanson, 2005; Martinez-Sanchez et al., 2008). Feelings of isolation, indicated by Ahmadi et al. (2000), Curseu et al. (2008) and Mann et al. (2000) were not raised as concerns by participants and, again, this finding could possibly be attributed to the companies commitment to teleworking and to the well-facilitated change to this form of virtual working arrangement, as noted by participants.

Two of the challenges of teleworking that were highlighted relate to the absence of training for teleworkers and the long hours worked. Akkirman and Harris (2005), Horwitz et al. (2006) and Tietze and Musson (2003) suggest that on-going training is an essential component to the success of a virtual working arrangement. The reported lack of training may impact the long-term sustainability and performance of teleworking arrangements. Long working hours may lead to burn out as has been noted by Mann et al. (2000) and accordingly, productivity may be affected.

Teleworking requirements can be expected to differ between organisations resulting in no single 'fail-safe' model (Morgan, 2004) and, as a result, the present study merely provided insights into this practice gained from employees within selected companies. Within this parameter, the following broad recommendations are made to South African organisations:

- Organisation should adopt pilot programmes (Morgan 2004) to determine the suitability of teleworking arrangements prior to the investment in capital cost. Pilot studies would allow organisations to test the processes required and establish benchmarks upon which to develop teleworking arrangements to address, amongst other things, organisational flexibility, based on the benefits and challenges to employees that have been identified in the present study.

- Specific human resource policies and organisational development strategies for teleworking must form part of teleworking arrangements to ensure that before entering 
into the new arrangement, each party is fully aware of the potential expectations, benefits and challenges.

- Managers of teleworkers will need to adjust their management styles and performance measurement processes to include the changes in working conditions of personnel and to ensure that performance management still forms an integral part of the manager-employee relationship (Stanford, 2003). The benefits of teleworking may be diluted if insufficient objective performance management does not ensure that the teleworker can still progress in the organisation although not being physically present.

- Attention must focus on the ongoing training of teleworkers, as would be the case for those employees who work in traditional work arrangements. Creative processes should be devised to incorporate teleworkers into the existing 'office' culture of the greater organisation.

- Teleworking can be utilised as part of an organisation's wellness programme and as a recruitment and retention tool to improve the overall desirability of an organisation to potential employees (Baruch, 2003; Heneman \& Greenberger, 2002). At the same time, organisations that take part in 'green' initiatives to reduce their impact on the environment could integrate teleworking into the strategy to achieve the objectives of this initiative (Siha \& Monroe, 2006).

In the course of the study, the following limitations were encountered:

- $\quad$ The majority of participants were White $(84.1 \%)$, largely the views of participants from other ethnic groups were not captured. In addition, participants were drawn from only three companies and sample numbers were small within each company. Accordingly, the findings may not be representative of all teleworkers nor of the actual conditions of teleworking in the specific industries represented and caution must be observed in generalising the findings of the study to other groups and other organisations.

- $\quad$ The majority of participants $(66.7 \%)$ had teleworked for less than two years in their companies and therefore, may have constituted a sample of participants who did not have sufficient exposure to this form of work arrangement to comment knowledgeably on the subject.

- The possibility always exists in surveys that participants may not have correctly understood the questions or may have believed that they could be identified in some way and, accordingly, responses may have been influenced. The verification of the accuracy of a percentage of responses aimed to address this issue.

- The study addressed only the perceived benefits and challenges of teleworking arrangements as they pertain to individual employees. No attempt was made to identify the organisational benefits and challenges of this form of work arrangement and the findings and recommendations must be viewed within this context.

Research on teleworking in South Africa is sparse and the present study was an attempt to begin addressing this gap. Possible research avenues that could be beneficial to local companies in terms of developing ideas in this area include:

- Identifying and quantifying the benefits and challenges of teleworking arrangements to organisations themselves, as distinct from the potential benefits and challenges for employees. Such research could include exploring the potential benefits of cost reductions, greater employee productivity and increased staff retention.

- Documenting potential social savings and positive impacts on the environment and on society in general, if teleworking had to be adopted as a work arrangement by a large number of local organisations.

- Identifying how teleworking arrangements could impact employee retention and talent management in the local context.
- Investigating appropriate reward structures for different groups of teleworkers to obtain optimal performance from such teleworkers within the context of different organisational settings.

Teleworking arrangements are on the increase globally because of the clear benefits offered by these arrangements in the current business environment. South African organisations have yet to capitalise on this new employment trend and the benefits that it has to offer. The study aimed to highlight the potential benefits of this work practice for employees as well as to highlight issues that may need to be addressed if this work practice is introduced. If the future projection of the number of international teleworkers is correct, it is imperative that South African organisations begin to understand how this form of work arrangement could be used to advance competitiveness.

\section{ACKNOWLEDGEMENT}

The authors wish to extend their sincere appreciation to $\mathrm{Mr}$ Richard Devey, Head of Statkon, University of Johannesburg, for his comments on methodology and data analysis.

\section{REFERENCES}

Ahmadi, M., Helms. M., \& Ross, T. (2000). Technological developments: Shaping the teleworking environments of the future. Facilities Journal, 18(1/2), 83-89.

Akkirman, A.D., \& Harris, D.L. (2005). Organizational communication satisfaction in the virtual workplace. Journal of Management Development, 24(5), 397-409.

Allert, J. (2001). You're hired, now go home. Training and Development, 55(3), 54-58.

Babbie, E., \& Mouton, J.J. (2009). The practice of social research. 9th edn. Cape Town: Oxford University Press.

Bal, J., \& Teo, P.K. (2001). Implementing virtual teamworking: Part 3 - A methodology for introducing virtual teamworking. Logistics Information Management, 14(4), 276-292.

Baruch, Y. (2003). The desert generation: Lessons and implications for the new generation of people management. Personnel Review, 33(2), 241-256.

Baruch, Y., \& Yuen, Y. (2000). Inclination to opt for teleworking: A comparative analysis of United Kingdom versus Hong Kong employees. International Journal of Manpower, 21(7), 531-539.

Beastley, R.E., Lomo-David, E., \& Seubert, V.R. (2001). Telework and gender: Implications for the management of information technology professionals. Industrial Management and Data Systems, 101(9), 477-482.

Beasty, C. (2005). Virtual contact centres need some fine-tuning. Customer Relationship Management, 9(6), 13.

Conner, D.S. (2003). Social comparison in virtual work environments: An examination of contemporary referent selection. Journal of Occupational and Organizational Psychology, 76, 133-147.

Curseu, P.L., Schalk, R., \& Wessel, I. (2008). How do virtual teams process information? A literature review and implications for management. Journal of Managerial Psychology, 23(6), 628-652.

Diefenbach, T. (2007). The managerialistic ideology of organizational change management. Journal of Organizational Change Management, 20(1), 126-144.

Dwyer, R.J. (2009). Prepare for the impact of the multigenerational workforce! Transforming Government: People, Process and Policy, 3(2), 101-110.

Furst, S.A., Reeves, M., Rosen, B., \& Blackburn, R.S. (2004). Managing the life cycle of virtual teams. Academy of Management Executive, 18, 6-20.

Gibson, V. (2003). Flexible working needs flexible space? Towards an alternative workplace strategy. Journal of Property Investment and Finance, 21(1), 12-22.

Grover, R., \& Vriens, M. (2006). The handbook of marketing research. Uses, misuses, and future advances. London: SAGE Publications Inc. 
Hamilton, E.A., Gordon, J.R., \& Whelan-Berry, K.S. (2006) Understanding the work-life conflict of never-married women without children. Women in Management Review, 21(5), 393-415.

Helms, M., \& Raiszadeh, F. (2002). Virtual offices: Understanding and managing what you cannot see. Work Study, 51(4/5), 240-247.

Heneman, R.L., \& Greenberger, D.B. (2002). Human resource management in virtual organizations. Columbus, Ohio: Ohio State University.

Horwitz, F.M., Bravington, D., \& Silvis, U. (2006). The promise of virtual teams: Identifying key factors in the effectiveness and failure. Journal of European Industrial Training, 30(6), $472-494$

Hughes, V., \& Love, P.E.D. (2004). Toward cyber-centric management of policing: Back to the future with information and communication technology. Industrial Management and Data Systems, 104(7), 604-612.

Hunsaker, P.L. \& Hunsaker, J.S. (2008). Virtual teams: A leader's guide. Team Performance Management, 14, 86-101.

Ilozor, D.B., \& Ilozor, B.D. (2002). Australian teleworking: Management communication strategies. Logistics Information Management, 15(2), 80-87.

Ingham, J. (2006). Closing the talent management gap. Strategic HR Review, 5(3), 20-23.

Jackson, P., Gharavi, H., \& Klobas, J. (2006). Technologies of the self: Virtual work and the inner panopticon. Information Technology and People, 19(3), 219-243.

Johnson, J. (2004). Flexible working: Changing the manager's role. Management Decision, 42(6), 721-737.

Johnson, J. (2005). The virtual workplace: The price is right. Network World, 22(36), 37.

Kepczyk, R. (1999). Evaluating the virtual office. Ohio CPA Journal, 58(2), 16-17.

Kowalski, K.B., \& Swanson, J.A. (2005). Critical success factors in developing teleworking programs. Benchmarking: An International Journal, 12(3), 236-249.

Kurland, N., \& Egan, T. (1999). Teleworking: Justice and control in the virtual organization. Organization Science, 10(4), 500513.

Langa, G.Z., \& Conradie, D.P. (2003). Perceptions and attitudes with regard to teleworking among public sector officials in Pretoria: Applying the Technology Acceptance Model (TAM). Communicatio, 29(1\&2), 280-296.

Lardi-Nadarajan, K. (2008). Breathing a second life into the synthetic worlds. New York: Deloitte MCS Limited.

Lim, V.K.G., \& Teo, T.S.H. (2000). To work or not to work at home. Journal of Managerial Psychology, 15(6), 560-586.

Macky, K., Gardner, D., \& Forsyth, S. (2008). Generational differences at work: Introduction and overview. Journal of Managerial Psychology, 23(8), 857-861.

Mann, S., Varey, R., \& Button, W. (2000). An exploration of the emotional impact of teleworking via computer-mediated communication. Journal of Managerial Psychology, 15(7), 668-690.

Martinez-Sanchez, A., Perez-Perez, M., Vela-Jimenez, M.J., \& de-Luis Carnicer, P. (2008). Telework adoption, change management, and firm performance. Journal of Organizational Change Management, 21(1), 7-31.

Meadows, V. (2007). Versatile bureaucracy: A telework case study. The Public Manager, 36(4), 33-37.

Meyer, J.P., Srinivas, E.S., Lal, J.B., \& Topolnytsky, L. (2007) Employee commitment and support for an organizational change: Test of the three-component model in two cultures. Journal of Occupational and Organizational Psychology, 180, $185-211$.

Moore, S. (1999). Understanding and managing diversity among groups at work: Key issues for organisational training and development. Journal of European Industrial Training, 23(4/5), 208-218.

Morgan, R.E. (2004). Teleworking: An assessment of the benefits and challenges. European Business Review Journal, 16(4), 344357.

Moustafa-Leonard, K. (2007). Trust and the managersubordinate dyad: Virtual work as a unique context. Journal of Behavioral and Applied Management, 8(3), 197-201.
Nandhakumar, J., \& Baskerville, R. (2006). Durability of online teamworking: Patterns of trust. Information Technology and People, 19(4), 371-389.

Nortje, H., Van Brakel, P.A., \& Rensleigh, C. (2004). Information environment of teleworkers in South Africa. South African Journal of Information Management, 6(1), Retrieved February 22, 2010, from www.journals.co.za/ej/ejour_info.html

O'Brien, T., \& Hayden, H. (2007). Flexible work practices and the LIS sector: Balancing the needs of work and life? Library Management, 29(3), 199-228.

Odendaal, A., \& Roodt, G. (2002). Australian and South African perspectives on the implementation of flexible work practices (FWP): An exploratory study. SA Journal of Industrial Psychology/ SA Tydskrif vir Bedryfsielkunde, 29(3), $75-82$.

Panteli, N., \& Duncan, E. (2004). Trust and temporary virtual teams: Alternative explanations and dramaturgical relationships. Information Technology E People, 17(4), 423-441.

Patrickson, M. (2002). Teleworking: Potential employment opportunities for older workers? International Journal of Manpower, 23(8), 704-715.

Porter, G., \& Kakabadse, N.K. (2006). HRM perspectives on addiction to technology and work. Journal of Management Development, 25(6), 535-560.

Reynolds, N., Diamantopoulos, A., \& Schegelmilch, B. (1993). Pretesting in questionnaire design: A review of the literature and suggestions for further research. Journal of Market Research Society, 35(2), 171-173.

Road Traffic Management Corporation. (2008). Road traffic report. Retrieved March 26, 2009, from http://www.arrivealive. co.za/documents/March_2008_-_Road_Traffic_Report March_2008.pdf

Shekhar, S. (2006). Understanding the virtuality of virtual organisations. Leadership $\mathcal{E}$ Organizational Development Journal, 27(6), 465-483.

Siha, S.M. \& Monroe, R.W. (2006). Teleworking's past and future: A literature review and research agenda. Business Process Management Journal, 12(4), 455-482.

Smith, I. (2005). Continuing professional development and workplace learning. Resistance to change - recognition and response. Library Management, 26(8/9), 519-522.

Sperling, D., \& Yeh, S. (2009). Low carbon fuel standards. Issues in Science and Technology, 25(2), 57-66.

Stanford, P. (2003). Managing remote workers. Executive Excellence, 20(6), 6-7.

Sundaram, D.S., \& Webster, C. (2000). The role of nonverbal communication in service encounters. Journal of Services Marketing, 14(5), 378-391.

Thorne, K. (2005). Designing virtual organizations: Themes and trends in political and organisational discourses. Journal of Management Development, 24(7), 580-607.

Tidd, R. (1999). Establishing your virtual office. Taxes, 77(6), 6-7.

Tietze, S., \& Musson, G. (2003). The times and temporalities of home-based telework. Personal Review, 32(4), 438-455.

Vakola, M., \& Wilson, I.E. (2004). The challenge of virtual organisation: Critical success factors in dealing with constant change. Team Performance Management, 10(5/6), 112-120.

Watad, M.M., \& Will, P.C. (2003). Telecommuting and organisational change: A middle-managers' perspective. Business Process Management Journal, 9(4), 459-472.

Watson-Manheim, M.B., Chudoba, K.M., \& Crowston, K. (2002). Discontinuities and continuities: A new way to understand virtual work. Information Technology and People, 15(3), 191209.

Wiesenfeld, B.M., Raghuram, S., \& Garud, R. (2001). Organizational identification among virtual workers: The role of need affiliation and perceived work-based social support. Journal of Management, 2, 213-229.

Wilsker, C. (2008). Unleashing the hidden productivity of your small business. New York: Avaya.

Zikmund, W. (2003). Business research methods. Mason, Ohio: Thomson: South-Western. 